\title{
An Environmental Impact Assessment of Perfluorocarbon Thermal Working Fluid Use On Board Crewed Spacecraft
}

\author{
Jay L. Perry \\ National Aeronautics and Space Administration \\ William A. Arnold \\ ZIN Technologies, Inc.
}

\begin{abstract}
The design and operation of crewed spacecraft requires identifying and evaluating chemical compounds that may present reactivity and compatibility risks with the environmental control and life support (ECLS) system. Such risks must be understood so that appropriate design and operational controls, including specifying containment levels, can be instituted or an appropriate substitute material selected. Operational experience acquired during the International Space Station (ISS) program has found that understanding ECLS system and environmental impact presented by thermal control system working fluids is imperative to safely operating any crewed space exploration vehicle. Perfluorocarbon fluids are used as working fluids in thermal control fluid loops on board the ISS. Also, payload hardware developers have identified perfluorocarbon fluids as preferred thermal control working fluids. Interest in using perfluorocarbon fluids as thermal control system working fluids for future crewed space vehicles and outposts is high. Potential hazards associated with perfluorocarbon fluids are discussed with specific attention given to engineering assessment of ECLS system compatibility, compatibility testing results, and spacecraft environmental impact. Considerations for perfluorocarbon fluid use on crewed spacecraft and outposts are summarized.
\end{abstract}

\section{INTRODUCTION}

The selection of a thermal control system working fluid for a spacecraft is a critical trade for developing future vehicles that will enable future crewed space exploration initiatives. The National Aeronautics and Space Administration (NASA) traditionally uses single phase active thermal control (ATC) systems comprised of separate internal and external circulating fluid loops. Vehicles presently operated by the NASA use water for the internal working fluid. The International Space Station (ISS) uses ammonia for the U.S. Segment's external ATC sys- tem working fluid while the Shuttle uses dichlorofluoromethane (Refrigerant 21).

While effective, opportunity exists to reduce overall thermal control system mass by using a single fluid ATC system. This opportunity resides in using fluorocarbon fluids to reduce heat transfer systems based on two fluids, such as water and ammonia, thermally connected via a heat exchanger to a single fluid loop with no heat exchangers. The potential benefits associated with using a single ATC working fluid include the following:

1. Fewer heat exchangers, particularly those involved with radiative heating

2. Fewer physical connections leading to less potential for leaks

3. Reduced ATC system launch mass

4. Reduced ATC system volume

5. Higher operating efficiency due to direct thermal exchange

In addition, a multi-component fluorocarbon fluid mixture might be able to take the place of current flash evaporators and ammonia boilers since each component has a unique boiling point. The result could be a drastic reduction of system size, weight, complexity and power consumption while maximizing efficiency.

Multiple challenges exist when selecting a working fluid for a crewed spacecraft's ATC system. Specific attributes are desired not only for optimizing ATC system performance but also for ensuring minimal impacts to the cabin environment during all mission phases. The fluid selected for the ATC system must be demonstrated to possess the desired thermal control performance characteristics, to present a minimal health risk to the crew, and to be compatible with on-board life support systems. Several candidate working fluids have been identified that possess promising thermal control performance characteristics. To determine whether these fluids pre- 
sent minimal impacts to the cabin environment and the ECLS system equipment, evaluation must be conducted.
Specific areas of interest to the cabin environmental impact assessment are the following:

\begin{tabular}{|c|c|c|c|}
\hline TRADE NAME & CONSTITUENT & COMPOSITION & $\begin{array}{c}\text { CAS } \\
\text { NUMBER }\end{array}$ \\
\hline HFE-7000 & 1-methoxyheptafluoropropane & $>99.5 \%$ & $375-03-1$ \\
\hline HFE-7100 & $\begin{array}{l}\text { Methyl nonafluoroisobutyl ether } \\
\text { Methyl nonafluorobutyl ether }\end{array}$ & $\begin{array}{l}20-80 \% \\
20-80 \%\end{array}$ & $\begin{array}{l}163702-08-7 \\
163702-07-6\end{array}$ \\
\hline HFE-7200 ${ }^{a}$ & $\begin{array}{l}\text { Ethyl nonafluoroisobutyl ether } \\
\text { Ethyl nonafluorobutyl ether }\end{array}$ & $\begin{array}{l}20-80 \% \\
20-80 \%\end{array}$ & $\begin{array}{l}163702-06-5 \\
163702-05-4\end{array}$ \\
\hline FC-72 Fluorinert ${ }^{\mathrm{a}}$ & $\mathrm{C}_{6}$ perfluoro compounds & $100 \%$ & $86508-42-1$ \\
\hline FC-87 Fluorinert ${ }^{a}$ & $\mathrm{C}_{5}$ to $\mathrm{C}_{18}$ perfluoro compounds & $100 \%$ & $86508-42-1$ \\
\hline Galden HT 55 & \multirow{3}{*}{ Hexafluoropropene polyether } & \multirow{3}{*}{$100 \%$} & \multirow{3}{*}{$69991-67-9$} \\
\hline Galden HT $135^{b}$ & & & \\
\hline Galden HT $170^{\mathrm{b}}$ & & & \\
\hline
\end{tabular}

1. Chemical composition of the fluid

2. Water solubility of fluid components and impacts to ECLS water processing systems

3. Volatility of fluid components, relative ease of removal, and impacts to ECLS air processing systems

4. Thermal stability and decomposition products of fluid components, including impurities

5. Reactivity

6. Relative toxicity

Water solubility, volatility, and ease of removal address at a cursory level the potential impacts to ECLS equipment performance including their ability to maintain a cabin environment suitable to support the crew in the presence of leaked ATC system working fluid. Such ATC system leaks may be gross leaks or fugitive emissions resulting from slow leaks from fluid couplings, valves, pumps, or other potential leak paths.

Likewise, thermal stability and decomposition products along with reactivity are evaluated based on cursory data to recommend whether a particular class of fluids is compatible with ECLS equipment process conditions. Some ECLS equipment may operate at high temperature and the potential for leaked ATC system fluid to thermally decompose to hazardous products must be understood.

Reactivity addresses compatibility with ECLS equipment employing reactive adsorbents such as lithium hydroxide (LiOH). Relative toxicity is evaluated by NASA toxicologists who set spacecraft maximum allowable concentrations (SMACs). The toxicologists' evaluation is important for engineers to determine the magnitude of the trace contaminant control challenge that the fluid may present to a future spacecraft or space habitat TCCS design. However, for early evaluation, recommended exposure data from vendor literature is considered sufficient for early screening purposes.

\section{COMPATIBILITY ASSESSMENT OF CANDIDATE ATC SYSTEM FLUIDS}

Candidate fluorocarbon-based ATC system fluids are listed by Table 1. These fluids are evaluated for ECLS system compatibility using the ISS as the reference system. Products include the Novec ${ }^{\mathrm{TM}}$ engineered fluid HFE series and Fluorinert ${ }^{\mathrm{TM}}$ fluids manufactured by $3 \mathrm{M}$ Company and several Galden HT fluids manufactured by Solvay Solexis, Inc. Data obtained from technical literature provide the main body of basic information for use the assessment. Journals were also consulted with respect to conditions of thermal decomposition. Table 1 also provides a summary of the chemical composition and Chemical Abstracts Service (CAS) reference number of the major constituents comprising each fluid.

\section{FLUID MAJOR COMPONENTS}

The candidate HFE- 7000 series fluids can be characterized as a whole as alkyl perfluoroalkyl ethers. HFE-7100 and HFE-7200 are a combination of 2 compounds while HFE-7000 is $>99 \%$ pure 1-methoxyheptafluoropropane. Independent evaluation of HFE-7000 samples at Rutgers University by capillary gas chromatography-mass spectrometry (GC-MS) in electron ionization and negative ion chemical ionization modes of operation found the neat liquid to be $>99.7 \%$ 1-methoxyheptafluoropropane with chemically similar perfluorocarbons, perfluorocarbon hydrides, and perfluoroalkyl ethers detected as impuri- 
ties. As well, trace amounts of sulfur-containing and a chloride compound were observed.[1]

Similar to the HFE-7000 series, the Galden HT product line is composed of perfluoroalkene ethers; however, the compounds are arranged in polymer chains. Purity of the candidate ATC system fluids from the Galden HT product line has not yet been independently tested.

The Fluorinert ${ }^{\dagger M}$ products are comprised of a mixture of perfluorinated compounds. FC-72 contains $\mathrm{C} 6$ perfluoro compounds while $\mathrm{FC}-87$ contains $\mathrm{C}_{5}-\mathrm{C}_{18}$ perfluoro compounds. The Fluorinert ${ }^{\mathrm{TM}}$ products range widely in purity. Of these two products, FC-72's purity has been evaluated independently by Rutgers University.[2] This evaluation found FC-72 to contain the major constituents summarized by Table 2 .

Impurities in an ATC system working fluid must be considered as part of the overall environmental impact assessment. Unfortunately the MSDS and technical literature typically do not provide details about impurities. As can be seen, FC-72 is not a highly pure fluid although its technical literature states that it is composed of $100 \%$ C6 fluorocarbon compounds. While technically correct, the MSDS omits key information that is important for thoroughly evaluating the fluid's suitability.

It is important to understand the nature of impurities for various reasons. Chief among these is chemical stability. For example, strait carbon chain perfluorinated compounds are typically chemically inert. However if oxygen or hydrogen atoms replace any of the fluorine atoms in the molecule, they become more reactive and susceptible to thermal decomposition.[3, 4] Testing to determine neat fluid purity as well as testing under anticipated ECLS system process conditions is necessary to fully understand the hazards presented by thermal decomposition. In general, the more pure fluids are considered to be better choices as overall chemical complexity is lower leading to a more simple ECLS compatibility assessment.

\section{SOLUBILITY IN WATER AND IMPACTS TO ECLS WATER PROCESSING SYSTEMS}

Solubility in water is an important consideration for any fluid that may be used in bulk on board a crewed spacecraft. Experience has found that highly water-soluble compounds can present significant challenges to onboard water purification processes.[5]

Solubility in water for the candidate fluids ranges from "insoluble" to as high as $\sim 20 \mathrm{ppm}$ by weight $\left(\mathrm{ppm}_{\mathrm{w}}\right)$. Table 3 summarizes the solubility in water of the candidate fluids reported in technical literature. The HFE7200 product has the highest solubility in water at $\sim 20$ $\mathrm{ppm}_{\mathrm{w}}$. The HFE-7100 fluid follows at $12 \mathrm{ppm}_{\mathrm{w}}$. Solubility in water of the FC-72 and FC-87 Fluorinert ${ }^{\mathrm{TM}}$ fluids are both $<5 \mathrm{ppm}_{\mathrm{w}}$. All of the Galden HT fluids are described as "insoluble". Specific information on the HFE-7000 fluid is not provided in technical literature but it can be assumed that the solubility in water will be similar in magnitude as the other HFE fluids or less due to its higher vapor pressure.

In comparison, the solubility of oxygen in water at $25^{\circ} \mathrm{C}$ is $39.45 \mathrm{ppm}_{\mathrm{w}} \cdot[6]$ Therefore the potential impacts presented by the candidate perfluorinated compound ATC system fluids to the water processing systems on board the ISS or any similar water purification system on board future space vehicles can be projected to be negligible.

\begin{tabular}{|l|c|}
\hline \multicolumn{1}{|c|}{ COMPONENT } & PERCENTAGE \\
\hline n-perfluorohexane & 73.2 \\
\hline Perfluoro-2-methylpentane & 17.89 \\
\hline Perfluoro-3-methylpentane & 5.95 \\
\hline Perfluorocyclohexane & 1.1 \\
\hline Perfluorodimethylbutane $^{*}$ & 1.72 \\
\hline Perfluoromethylcyclopentane $^{*}$ & 0.13 \\
\hline
\end{tabular}

Table 2. FC-72 Fluorinert ${ }^{\mathrm{TM}}$ Major Components

\begin{tabular}{|l|c|}
\hline \multicolumn{1}{|c|}{ FLUID } & SOLUBILITY IN WATER \\
\hline HFE-7000 & N/A \\
\hline HFE-7100 & $12 \mathrm{ppm}_{\mathrm{w}}$ \\
\hline HFE-7200 & $<20 \mathrm{ppm}_{\mathrm{w}}$ \\
\hline FC-72 Fluorinert & $<5 \mathrm{ppm}_{\mathrm{w}}$ \\
\hline FC-87 Fluorinert & $<5 \mathrm{ppm}_{\mathrm{w}}$ \\
\hline Galden HT 55 & Insoluble \\
\hline Galden HT 135 & Insoluble \\
\hline Galden HT 170 & Insoluble \\
\hline
\end{tabular}

Table 3. Solubility in Water of Candidate ATC System Working Fluids

\section{VOLATILITY AND IMPACTS TO ECLS CABIN ATMOSPHERE PURIFICATION SYSTEMS}

The vapor pressures of candidate ATC system fluids range from $<0.13 \mathrm{kPa}$ to $81.1 \mathrm{kPa}$ as shown by Table 4 . FC-87 Fluorinert ${ }^{\mathrm{TM}}$ possesses the highest vapor pressure at $81.1 \mathrm{kPa}$ followed by HFE-7000 at $64.6 \mathrm{kPa}$. The other HFE-7000 series fluids have decreasing vapor pressures reflecting the shift from a methyl-substituted to an ethyl-substituted molecule. Galden HT series fluids possess vapor pressures ranging from $<0.13 \mathrm{kPa}$ to 29.9 
$\mathrm{KPa}$. This range is probably due to the extent of polymerization in the specific fluid with longer polymer chains possessing the lowest vapor pressure. From the environmental impact assessment, the fluids possessing the lowest vapor pressures are the most desirable.

The combination of high molecular weight and low vapor pressure make compounds amenable to easy removal from the cabin atmosphere by activated carbon. Therefore, it is anticipated that the vapors of all candidate fluids can be removed with relative ease from the cabin atmosphere in the event of a leak by atmospheric revitalization (AR) and purification equipment typically used on board crewed spacecraft. For example, the ISS'S

\begin{tabular}{|l|c|}
\hline \multicolumn{1}{|c|}{ FLUID } & $\begin{array}{c}\text { VAPOR PRESSURE } \\
(\mathbf{k P a})\end{array}$ \\
\hline HFE-7000 & 64.6 \\
\hline HFE-7100 & 26.9 \\
\hline HFE-7200 & 14.5 \\
\hline FC-72 Fluorinert & 30.9 \\
\hline FC-87 Fluorinert & 81.1 \\
\hline Galden HT 55 & 29.9 \\
\hline Galden HT 135 & 1.1 \\
\hline Galden HT 170 & $<0.13$ \\
\hline
\end{tabular}

Table 4. Vapor Pressure of Candidate ATC System Working Fluids

trace contaminant control equipment-the U.S. Segment's trace contaminant control subassembly (TCCS) and the Russian Segment's micro-impurity removal assembly or BMP-both contain fixed beds of activated carbon designed specifically to remove trace components from the cabin atmosphere. In particular, the TCCS's activated carbon bed is designed to remove dichloromethane, a much lighter, more volatile halocarbon compared to the candidate fluids. Given this more challenging design point, it is expected that the TCCS will be capable of removing vapors of any of the candidate ATC system fluids from the cabin atmosphere.

Also the compounds contained in the candidate fluids may be removed in the U.S. Segment's carbon dioxide removal assembly (CDRA) desiccant and $\mathrm{CO}_{2}$ adsorbent beds. The desiccant bed contains layers of silica gel and $13 \mathrm{X}$ zeolite and the $\mathrm{CO}_{2}$ adsorbent bed contains $5 \mathrm{~A}$ zeolite. Testing conducted by Lockheed in 1991 indicated that 1,1,2-trifluoro-1,2,2-trifluoroethane (Freon 113 ) is removed by the CDRA at a net $39 \%$ efficiency.[7] Thirty-one percent of the Freon 113 entering the CDRA was removed in the desiccating stage while the $\mathrm{CO}_{2}$ adsorption stage removed $25 \%$. Net removal indicates some desorption back to the CDRA's exhaust when the desiccating stage is regenerated. Because the compounds under evaluation are larger molecules than Freon 113, it is possible that they may be removed by the CDRA or a similar cabin atmosphere purification process, at comparable or lower efficiency. The type of zeolite, its pore size, and the molecular size affect the removal performance.

Lockheed's testing did not indicate any degradation in the CDRA's ability to remove $\mathrm{CO}_{2}$; however, the testing was not designed to evaluate life-related issues pertaining to $\mathrm{CO}_{2}$ and contaminant co-adsorption. Due to their low volatility and the fact that the sorbent beds are heated to $200{ }^{\circ} \mathrm{C}$ during regeneration, it is not certain that either an undesirable buildup on the beds of the candidate ATC system fluids producing degraded performance or undesirable thermal degradation products could be produced during regeneration. Testing is necessary to fully characterize the potential for and extent of such impacts.

For a spacecraft employing vacuum-swing or combined vacuum/thermal swing adsorption processes for cabin atmosphere purification, care must be taken to ensure that compounds possessing high molecular weight low vapor pressure do not enter the regenerable adsorbent beds. Such compounds may foul the beds over time reducing their useful life. To this end, all efforts should be made to ensure persistent fugitive emissions into the cabin do not occur or appropriate guard beds are included as part of the atmosphere revitalization process design.

\section{THERMAL STABILITY AND DECOMPOSITION}

Thermal stability of perfluorinated compounds is highly important to assessing compatibility with spacecraft ECLS system processes because some process conditions operate at temperatures of $400{ }^{\circ} \mathrm{C}$ or higher. According to MSDS literature, perfluorinated compounds may decompose to hydrogen fluoride (HF), carbonyl fluoride $\left(\mathrm{COF}_{2}\right)$, perfluoroisobutylene (PFIB), carbon monoxide (CO), and carbon dioxide $\left(\mathrm{CO}_{2}\right)$ when exposed to high temperatures over a prolonged period. All of these are undesirable thermal degradation products. Early assessment of FC-72 Fluorinert ${ }^{\mathrm{TM}}$, a product similar to FC-87 and HFE-7100 series fluids by NASA toxicology experts recommended that the "amount of volatile material used on board the ISS should be kept to a minimum" because of the limitations of atmosphere purification resources on board.[8]

While means exist to remove $\mathrm{CO}$ and $\mathrm{CO}_{2}$ from the cabin atmosphere, the other compounds-HF, $\mathrm{COF}_{2}$, and PFIB-are highly toxic and much more difficult to remove. In all cases, vendor MSDS literature cautions against exposing the fluids to elevated temperatures for prolonged periods. MSDS temperature limit recommen- 
dations for the fluids range from $200^{\circ} \mathrm{C}$ to $300^{\circ} \mathrm{C}$. Specifically, FC-87 must not be heated above $200^{\circ} \mathrm{C}$ while HFE-7100 and HFE-7200 must not be heated above 300 ${ }^{\circ} \mathrm{C}$ to avoid thermal decomposition. Galden. HT fluids must not be heated above $290^{\circ} \mathrm{C}$. No specific temperature is provided for HFE-7000 so it must be assumed that its limit is similar to HFE-7100 and HFE-7200.

The predominant thermal decomposition product is HF. PFIB is typically produced at a rate 1,000 times lower than HF. However, the HF exposure limit is $3 \mathrm{ppm}_{\mathrm{v}}$ while that for PFIB is $0.01 \mathrm{ppm}_{\mathrm{v}}$. This still makes PFIB production a significant concern that must be addressed in more detail.

Due to the recommendations from MSDS literature and concerns for toxic hazard risks associated with some impurities found in the fluids, more rigorous evaluation and testing of thermal stability must be considered a requirement for any perfluorocarbon used as an ATC system working fluid.

\section{Thermal Stability Literature Review}

A literature review found that the conditions necessary to form PFIB require a perfluorocarbon-rich environment coupled with a very long exposure time in the presence of halogen gases. In the studies documented by references 3 and 4 , the experimental conditions involved sealing the perfluorocarbon under study in a tube by itself or with chlorine $\left(\mathrm{Cl}_{2}\right)$ or bromine $\left(\mathrm{Br}_{2}\right)$ gas followed by exposure to high temperature for at least 1 hour. These conditions are not representative of those typically found on board the crewed spacecraft or within their cabin air purification systems.

On board a crewed spacecraft such as the ISS, the perfluoro compound will be in the presence of excess oxygen in the cabin air and the residence time within the cabin air purification systems is relatively short. For example, the exposure time to high temperature surfaces within both the ISS TCCS catalytic oxidizer assembly $(\mathrm{COA})$ and solid-fuel oxygen generation system (Russian acronym TGK) is less than 1 second. The maximum estimated TCCS COA residence time is 0.67 seconds with a process temperature of $400{ }^{\circ} \mathrm{C}$. Residence time for the TGK is 0.76 seconds with exposed surface temperature no greater than $90^{\circ} \mathrm{C}$ for the TIK solid oxygen source cartridge. Typically, the TIK cartridge external surface temperature is $50^{\circ} \mathrm{C}$. The TIK cartridge is designed to withstand a maximum $450^{\circ} \mathrm{C}$ external surface temperature.[9] Both units are built from 300-series stainless steel alloys presently; however, a change to the TGK may change its construction to a titanium alloy. Neither alloy possesses catalytic properties under normal equipment operating conditions.
The literature survey findings indicate that oxygen plays a role by suppressing PFIB formation. Oxygen presence may result in other products such as hydrogen fluoride $(\mathrm{HF})$, carbon monoxide $(\mathrm{CO})$, carbonyl fluoride $\left(\mathrm{COF}_{2}\right)$, methane $\left(\mathrm{CH}_{4}\right)$, and carbon dioxide $\left(\mathrm{CO}_{2}\right)$.

Residence time is also important. For instance, an experiment that flowed perfluoropropene through a tube held at $510^{\circ} \mathrm{C}$ and 1 atmosphere to provide a 10-second contact time found no PFIB was formed. In contrast, a 7-hour exposure in a sealed tube at the same temperature condition found reaction products. PFIB was not found below $700^{\circ} \mathrm{C}$ in this experiment.

\section{Thermal Stability Testing}

The literature survey indicated that PFIB production is not expected in detectable quantities under normal ISS or future crewed spacecraft cabin air purification process operating conditions. To test this hypothesis and also investigate the potential for producing other harmful oxidation products, two testing activities were defined and executed. The first, conducted by the NASA's Marshall Space Flight Center, subjected FC-72 and $99 \%$ perfluoro-n-hexane to a sustained temperature condition of $250^{\circ} \mathrm{C}$ in a flowing gas stream in both oxidizing and nonoxidizing environments.[10] The second testing was conducted at Rutgers University to investigate the thermal stability of FC-72, 99\% perfluoro-n-hexane, and HFE-7000 under dynamic flow conditions representative of typical cabin air purification processes such as the ISS TCCS COA and the Russian TGK. $[1,2,11,12]$ In this testing, the composition of $3 \mathrm{M}$ Company FC-72, two samples of $99 \%$ perfluoro-n-hexane from different suppliers, and HFE-7000 were evaluated for impurities and for decomposition products when exposed to contact time and temperature conditions representative of the TCCS COA and Russian TGK.

\section{Thermogravimetric-Infrared Testing of Perfluorohexane Fluids}

Qualitative screening tests documented by reference 10 were accomplished at NASA Marshall Space Flight Center using a coupled thermogravimetric-infrared (TG-IR) analysis technique. The test specifically targeted the appearance of carbon double bonds that would qualitatively indicate the presence of PFIB. Samples of $3 \mathrm{M}$ Company FC-72 Fluorinert $^{\mathrm{TM}}$ and $99 \%$ perfluoro-nhexane from Aldrich Chemical Co. were exposed to a sustained temperature of $250{ }^{\circ} \mathrm{C}$. Exposure times exceeded 8 minutes. Results showed no evolution of functional groups containing carbon double bonds for all runs. Also, no signatures indicating other decomposition products were observed.

Dynamic Thermal Stability Testing of Perfluorohexane Fluids 
This testing conducted at Rutgers University and documented by references 1,11 , and 12 involved two steps. First was an evaluation of the purity of $3 \mathrm{M}$ Company FC72 and samples of $99 \%$ perfluoro-n-hexane from Aldrich Chemical Co. and F2 Chemicals Ltd. Second was a series of 5 flow tests representative of TCCS and TGK process conditions in both oxidizing and non-oxidizing environments. Analytical methods were gas chromatography/mass spectrometry (GC/MS) and gas chromatography with flame ionization detection (GC-FID).

The purity of $3 \mathrm{M}$ Company FC-72 observed is summarized in Table 2. In addition to the compounds reported in Table 2, trace and ultra-trace quantities of other compounds were noted. The sample from Aldrich Chemical Company contained $99.4 \%$ perfluoro-n-hexane with some $\mathrm{C}_{6}, \mathrm{C}_{8}$, and $\mathrm{C}_{10}$ perfluorocarbons. The F2 Chemicals Ltd. sample contained $99.7 \%$ perfluoro-n-hexane, $0.1 \%$ perfluorocyclopentane, and $0.2 \%$ perfluoro-2methylpentane.

Contact time and the temperature conditions exceeded the process conditions within the TCCS COA and Russian TGK. The TCCS COA operates at $400^{\circ} \mathrm{C}$ while exposed surfaces within the Russian TGK do not exceed $90^{\circ} \mathrm{C}$. For the experimental runs the contact time was $>1.2$ seconds with catalyst material packed in the reactor. This contact time accounts for catalyst interstitial volume only and is $\sim 79 \%$ greater than the actual 0.67 second contact time in the TCCS COA. When empty, the reactor provided $>8.7$-second contact time which far exceeds the Russian TGK contact time of 0.76 seconds.

Testing under simulated TCCS and TGK process conditions found that the perfluorohexane samples were not degraded under any conditions and no trace PFIB was detected above the method detection limit of $\sim 10 \mathrm{ppb}_{\mathrm{v}}$. No changes in inlet composition were observed from analyses of the outlet condition. No other oxidation products of concern were noted.

\section{Dynamic Thermal Stability Testing of HFE-7000}

Samples of HFE-7000 were also evaluated for thermal stability under the same dynamic conditions. Results are documented by reference 1 . Observed results indicate $57 \%-59 \%$ of the HFE-7000 is converted to nonvolatile thermal decomposition products. This leaves $41 \%-43 \%$ of the initial HFE- 7000 mass as volatile products. Carbon monoxide, carbon dioxide, and water vapor were also observed in the pyrolysis gas.

Under the experimental conditions, $100 \%$ of the primary component, 1-methoxyheptafluoropropane, as well as the sulfur-containing and chlorocarbon impurities decomposed. Several impurities, including perfluoroethane, perfluoropropane, and a perfluorocarbon hydride were unchanged. Methane was observed in the pyrolysis gas. This is likely due to the release of the methoxy group from HFE-7000's primary component. Since fluorine is a known strong oxidation catalyst poison, it is likely that perfluorocarbon radicals may also act as poisons. Combined with the very short contact time in the reactor, further decomposition of the methoxy group beyond its most stable form-methane-did not occur. No harmful products such as PFIB were observed.

\section{Summary of Thermal Stability Tests}

In summary, testing was conducted on FC-72 using 2 separate methods. In both sets of tests, no evidence of PFIB production was observed after exposure to a 250 ${ }^{\circ} \mathrm{C}$ condition for 8 minutes or $450{ }^{\circ} \mathrm{C}$ in the presence of TCCS catalyst in an oxidizing environment. HFE-7000 was also subjected to testing under simulated TCCS process conditions and decomposed completely. For all tests involving multiple analytical methods and two candidate ATC system fluids, no hazardous pyrolysis products were observed. Based on these results, the hypothesis that PFIB is not produced in measurable quantities under short exposure times and in the presence of excess oxygen as advanced by the literature survey is supported. Also, no other oxidation products of concern were observed.

\section{PREDICTED FC-72 IMPURITY EXTENT OF REACTION UNDER HIGH TEMPERATURE ECLS SYSTEM PROCESS CONDITIONS}

The experimental conditions used for assessing the decomposition of the components comprising FC-72 have been established to be conservative relative to ISS and likely for most future spacecraft ECLS system process conditions with respect to temperature and contact time. Further, the ECLS system process temperature conditions within the ISS TCCS and Russian TGK exceed the temperature where some branched carbon chain perfluorocarbon compounds may decompose to produce hazardous products such as PFIB according to references 3 and 4 . To understand the theoretical extent of PFIB production during contact with heated ECLS system process equipment and to better understand the ECLS testing results, reaction rate data and conditions favorable to PFIB formation must be considered. Therefore, literature sources documenting the potential for hazardous thermal decomposition product formation were evaluated with respect to the relevance of experimental conditions to ISS and future spacecraft ECLS system process conditions. Other literature sources were also reviewed to understand contributing and inhibiting factors associated with PFIB formation under high temperature conditions.

Comparison of Literature and ECLS System Process Conditions 
Review of references 3 and 4 that indicate the potential for hazardous thermal decomposition product formation found that the experimental conditions were specifically tailored to form pyrolysis products so that reaction mechanisms could be studied. Specifically, each 10mmole experimental sample under evaluation was sealed in a 10-ml glass tube and held at high temperature for 8 to 15 hours. During this time, pressure in the reaction volume could rise to $\sim 34$ atmospheres. To promote reaction, other compounds such as halogens or toluene were injected in some instances. All experiments were conducted in the absence of air or oxygen. This is a key point of departure from actual crewed spacecraft air quality control system process conditions. It is also important because studies conducted at Oak Ridge National Laboratories found that PFIB formation is suppressed in the presence of oxygen.[13,14] As well, references 13 and 14 as well as reference 15 indicate PFIB hydrolysis by moisture in the air will occur with $\mathrm{HF}$, $\mathrm{CO}, \mathrm{COF}_{2}$, and $\mathrm{CO}_{2}$ as the resulting products. Overall, the literature sources that indicate the potential for a hazard are meaningful only to the extent that reaction rate data are provided for perfluorocarbon compounds similar in structure to perfluoro-2,2-dimethylbutane, an impurity found in FC-72.

Because the experimental conditions with respect to residence time, pressure, and non-oxidizing conditions are not representative of those typically found within crewed spacecraft cabin air quality control system processes, references 3 and 4 are useful for information only. At most, these reference materials demonstrate that hazardous thermal decomposition products are produced under static conditions over a long contact time. Such conditions are extraordinary compared to those that exist within cabin air quality control process equipment on board the ISS or envisioned for future crewed spacecraft.

Even, so, the potential for thermal decomposition should not be taken lightly and efforts to best understand the situation presented by ATC system fluid leakage scenarios must be undertaken. Therefore, to achieve a complete, conservative assessment, reaction rate data from references 3 and 4 are considered for predictive purposes with appropriate adjustment to eliminate the effects of radical traps. It must be noted that, although highly likely under ECLS system process conditions, further reaction of PFIB with oxygen and moisture to form other products is not considered and, as such, the predictions that follow are considered to be conservative. The degree of conservatism, unfortunately, cannot be fully quantified except to apply the predictive technique as a check of the observed ECLS compatibility testing results.

Predicted Extent of Reaction
While review of the available literature on the subject of hazardous thermal decomposition products demonstrates that the documented experimental conditions are not representative of typical ECLS system process conditions, it is prudent to consider the reaction rate data contained in these sources as a potentially conservative means to estimate PFIB formation. Of the perfluorohexane isomers present in FC-72, the most likely to thermally decompose to PFIB is perfluoro-2,2dimethylbutane. Perfluoro-2,2-dimethylbutane, combined with perfluoro-2,3-dimethylbutane, comprise approximately $1.7 \%$ of FC-72. Of all the isomers, however, only perfluoro-2,2-dimethylbutane has the potential to thermally decompose at some ECLS system process conditions, such as those found in the ISS TCCS COA, to produce PFIB. All other isomers are not expected to decompose according to the cited literature.[16]

By using as a basis a rate constant at $181^{\circ} \mathrm{C}\left(0.77 \times 10^{-}\right.$ ${ }^{5} \mathrm{~s}^{-1}$ ) from reference 4 for a similar compound that may produce PFIB among its 3 decomposition products, a reasonable rate constant estimate at $400{ }^{\circ} \mathrm{C}$ is made using the Arrhenius equation.[17] The result is $0.78 \mathrm{~s}^{-1}$. This is a first order rate constant and does not reflect the enhancement of the rate constant in the presence of radical traps. Pressure effects on the rate constant are not considered because rate constant decrease is typically not observed until pressure falls below 26.7 kPa.[18]

\section{Theoretical PFIB Production in the TCCS at $400^{\circ} \mathrm{C}$}

For a case based on a planned ISS application in the Japanese Experiment Module (JEM) where $75 \mathrm{ml}$ (0.37 moles) of FC-72 leaks, the predicted cabin concentration of perfluoro-2,2-dimethylbutane is $1.74 \times 10^{-5} \mathrm{moles} / \mathrm{m}^{3}$. For the purposes of this assessment, it is conservatively assumed that the TCCS's activated carbon capacity is completely consumed and all the FC-72 and its impurities enter the COA. The maximum residence time in the TCCS's COA is 0.67 seconds. Using a solved form of a first order plug flow reactor mass balance equation, the single pass extent of reaction is $41 \% .[19,20]$ Keeping in mind that 3 or more different decomposition products result, the extent of reaction to PFIB is $13.5 \%$.

If it is assumed that the perfluoro-2,2-dimethylbutane isomer conservatively accounts for all of the $1.7 \%$ perfluorodimethylbutane impurity in FC-72, then the maximum PFIB concentration in the TCCS exhaust gases in the event of a $75-\mathrm{ml}$ release is $0.14 \mathrm{mg} / \mathrm{m}^{3}\left(0.02 \mathrm{ppm}_{\mathrm{v}}\right)$. PFIB is easily removed by activated carbon so the absolute maximum cabin concentration that may result from sustained FC-72 processing via the TCCS COA at an inlet concentration representative of a $75-\mathrm{ml} \mathrm{FC-72} \mathrm{leak}$ is $0.05 \mathrm{mg} / \mathrm{m}^{3}\left(6 \mathrm{ppb}_{\mathrm{v}}\right)$. Production, of course, is transient from a static leak as the FC-72 concentration in the cabin is reduced. 
Comparison to the Observed ECLS Compatibility Testing Results

Applying the rate constant data to the ISS T.CCS COA testing conducted by Rutgers University, the highest calculated extent of reaction predicts $\sim 0.01 \mathrm{mg} \mathrm{PFIB/ \textrm {m } ^ { 3 }}$ $\left(\sim 1.3 \mathrm{ppb}_{\mathrm{v}}\right)$ in the test gas effluent. This is far lower than the analytical method's $\sim 10 \mathrm{ppb}_{\mathrm{v}}$ detection limit. Therefore, the ECLS process experimental results are indeed expected because, even under the most conservative conditions the maximum amount of PFIB formed is predicted to be far below the analytical method detection limit.

\section{Considerations for PFIB Reaction in Humid Air}

It must be kept in mind that in the presence of oxygen and humidity and under higher temperature conditions encountered in some crewed spacecraft ECLS system processes, PFIB will very likely react further or its formation may be depressed. Other reaction products expected in humid air include $\mathrm{CO}, \mathrm{HF}, \mathrm{COF}_{2}$, and $\mathrm{CO}_{2}$. These effects are not quantified by available literature sources or ECLS compatibility testing data so cannot be accounted for in any risk assessment. Further testing using analytical methods that target these compounds is necessary to fully understand the role that oxygen and humidity play in PFIB's persistence under high temperature conditions. Also, the perfluoro-2,2-dimethylbutane isomer is present in lower quantities than assumed for this assessment. For example, an assay provided by the $3 \mathrm{M}$ Company indicates it is present at $0.74 \%$. Therefore, the calculated results are conservative by approximately a factor of 2 .

\section{Considerations for Removal by Activated Carbon}

Previous ECLS assessment documented by reference 21 found the equilibrium granular activated carbon (GAC) loading for perfluoro-n-hexane is $0.2 \mathrm{~g} / \mathrm{g} \mathrm{GAC}$. At this capacity, $>4,500$ grams or 2.7 liters of perfluorohexane is required to saturate the $22.7 \mathrm{~kg}$ of GAC in the $I S S$ TCCS charcoal bed assembly (CBA). Allowing for $20 \%$ operational margin, the total leakage required to saturate the CBA is 2.1 liters.

Similarly, the micropurification assembly (BMP) in the Russian On-orbit Segment (ROS) contains an expendable packed bed (FOA unit) containing $2 \mathrm{~kg}$ GAC and two regenerable packed beds (ZPL-1M units) containing $2.8 \mathrm{~kg}$ GAC combined. In total, the BMP may accommodate $\sim 960$ grams or $570 \mathrm{ml}$ of perfluorohexane. Its expendable GAC bed, however, can accommodate only 400 grams or $\sim 240 \mathrm{ml}$ of perfluorohexane.
In total, the maximum quantity of FC-72 that may be leaked into the ISS cabin leading to complete saturation of the TCCS and BMP is 2.6 liters. This amount includes $20 \%$ operational margin to account for the effects of coadsorption on activated carbon saturation. From a maintenance perspective, however, any leak exceeding 120 $\mathrm{ml}$ will require maintenance on the BMP to replace its expendable GAC bed and any leak exceeding 1 liter will require maintenance on the TCCS to replace the CBA. These amounts represent one-half the equilibrium capacity of the expendable activated carbon beds in the TCCS and BMP. Given that perfluorohexane is not water soluble, it is expected to have minimal impact on elution of previously adsorbed contaminants from GAC beds.

Comparatively, the FC-72 is one of the more difficult of the candidate ATC system fluids to remove using activated carbon adsorption. Ease of removal by activated carbon can be projected by examining the relative magnitude of the vapor pressure. Using this comparison, FC-87 and HFE-7000 are expected to be more difficult than FC-72 to remove from the cabin atmosphere. Galden HT 55 and HFE-7100 are projected to be removed with comparable ease to FC-72. The HFE-7200, Galden HT 135, and Galden HT 170 fluid components are expected to be removed much more easily than FC72. The latter fluids, especially Galden HT 135 and Galden HT 170, however, must be evaluated for their compatibility with regenerable cabin air quality control processes. Their very low vapor pressures may cause them to act as fouling agents for regenerable adsorbent media, especially for adsorbent media regenerated solely by vacuum swing processes.

\section{REACTIVITY}

Reactivity hazards noted for the candidate compounds are consistent for all. Essentially they must not be exposed to strong or non-aqueous alkali. Most spacecraft ECLS systems use granular lithium hydroxide ( $\mathrm{LiOH})$ either as the primary or backup means to remove $\mathrm{CO}_{2}$ from the cabin atmosphere. Based on vendor recommendations, it is not recommended to allow the candidate compounds to enter a $\mathrm{LiOH}$ bed unless specific testing indicates no reactivity issues exist for the expected range of cabin temperature and relative humidity conditions.

Typically, reaction of halocarbons over an alkali material requires elevated temperature for the reaction hazard to exist. However, only the Galden HT series literature notes a temperature threshold of $>100^{\circ} \mathrm{C}$ where the reactivity hazard may be present. The literature for the other fluids only state that contact with strong bases should be avoided and provide no guidance with respect to temperature. Given that there are potential incompatibilities with $\mathrm{LiOH}$, further investigation in this area is 
required if one of the candidate fluids is selected for use on board crewed spacecraft that use $\mathrm{LiOH}$ to remove carbon dioxide from the cabin atmosphere.

\section{RELATIVE TOXICITY}

Recommended industrial 8-hour exposure limits for the candidate fluids range from $75 \mathrm{ppm}_{\mathrm{v}}$ to $750 \mathrm{ppm}_{\mathrm{v}}$. The HFE-7000 fluid has the lowest industrial 8-hour exposure limit at 75 ppm $_{v}$. HFE-7100 has an industrial 8-hour exposure limit of $750 \mathrm{ppm}_{\mathrm{v}}$ while HFE-7200 has a limit of $200 \mathrm{ppm}_{\mathrm{v}}$. No exposure limit is available for FC-87 Fluorinert $^{\mathrm{TM}}$ and no inhalation hazards are noted; however, it is noted that "significant irritation" may occur in the event of skin or eye contact. Likewise, no exposure limit is established for the Galden HT series fluids but it is noted that they are potential eye, skin, and respiratory irritants. If selected for further study, any of the candidate fluids must be evaluated by toxicology experts to set spacecraft maximum allowable concentrations (SMACs).

\section{Comparisons to Acetone}

Some of the supplier literature compares the fluids to acetone. The 8-hour exposure limit for acetone is 500 $\mathrm{ppm}_{\mathrm{v}}$. Note also that acetone has a vapor pressure comparable to HFE-7100 and the high end of the Galden HT series fluids. The official 180-day SMAC for acetone is $22 \mathrm{ppm}_{\mathrm{v}}$.[22] While it is beyond the expertise of ECLS engineering to set exposure limits, by mere comparison, it can be anticipated that a potential SMAC for these compounds may be a factor of 23 lower than their 8-hour exposure limits. This could result in HFE-7000 being classified as more toxic than ammonia, one of the thermal working fluids presently in use by the NASA, which has a 180-day SMAC of $10 \mathrm{ppm}_{\mathrm{v}}$ [23] The HFE-7100 and HFE-7200 fluids may be less toxic than ammonia while it is not possible to speculate about FC-87 Fluorinert $^{\text {TM }}$ and the Galden HT series fluids.

Overall, it is repeated that if any of the candidate fluids are selected for use on board crewed spacecraft, a detailed assessment by toxicology experts will be required. Upon completing that analysis, a further detailed analysis of the ability of the spacecraft's ECLS system to control specific leakage scenarios to within the toxicologist's guidelines will be required.

\section{SUMMARY}

Eight candidate perfluoro compound ATC system working fluids have been described and evaluated by analysis to determine their potential environmental impact if used on board the ISS or future crewed spacecraft. All of the candidate fluids are minimally soluble in water and possess low vapor pressures.
Two of the candidate fluids, FC-72 and HFE-7000, have been subjected to thermal stability testing under conditions representative of ECLS system processes. No harmful decomposition products were observed during the tests. The FC-72 fluid was found to be more thermally stable than the HFE-7000 which was completely decomposed.

Impurities in the fluids must be considered for their potential to contribute to hazardous thermal decomposition products. Worst case assessment of impurities contained in FC-72 found the absolute worst case PFIB production under simulated ECLS system conditions to be well below air quality monitoring method detection limits.

All candidate fluids note reactivity hazards with strong or non-aqueous alkali. For this reason, compatibility studies with $\mathrm{LiOH}$ should be considered.

\section{CONCLUSION}

Based on data acquired from vendor and scientific literature supplemented with data from tests of two candidate fluids, conclusions regarding the environmental impact associated with using fluorocarbon ATC system fluids on board crewed spacecraft are the following:

1. The candidate fluids are no more soluble in water than oxygen and, therefore, are considered a negligible risk to ISS and future space vehicle and outpost water purification systems.

2. The vapors from the candidate fluids should be removed from the cabin atmosphere by GAC or other micro-porous adsorbents contained in typical spacecraft cabin atmosphere purification systems. Testing is prudent for high molecular weight components to address their potential for long-term fouling of regenerable bed processes.

3. Thermal stability issues must be addressed on a case wise basis. Process conditions in high temperature ECLS system equipment are typically greater than the recommended "not to exceed" temperatures leading to the risk that hazardous thermal decomposition products such as HF and PFIB may be produced and liberated into the cabin on contact with the heated surfaces. Specific testing of fluorocarbon fluids under representative ECLS system process conditions is required.

4. A significant reactivity hazard exists for all the candidate fluids with strong, non-aqueous alkali materials. If any of the candidate fluids are selected for use on board future crewed spacecraft or space outposts, a full evaluation of compatibility with granular $\mathrm{LiOH}$ over a range of temperature is necessary.

\section{ACKNOWLEDGMENTS}


The efforts of Mr. Tim Huff of NASA's Marshall Space Flight Center on the TGIR evaluation of FC-72 and Dr. Thomas Hartman of Rutgers University to evaluate the purity and dynamic thermal stability of FC-72, high purity n-perfluorohexane, and HFE-7000 fluids have contributed greatly to understanding the risks and environmental impact considerations associated with perfluorocarbon fluid use on board crewed spacecraft. Their efforts have proven indispensable to understanding the environmental impact of perfluorocarbon fluids on board crewed spacecraft and set a bench mark for future evaluation strategies.

Also, the dedication and assistance of the BXF Project and ZBOT Project teams to thoroughly evaluate the safety challenges presented by FC-72 and HFE-7000 fluids has been invaluable. These teams championed and sponsored the dynamic thermal stability testing for FC-72 and HFE-7000 fluids.

\section{REFERENCES}

.1. Hartman, T.G.: Mass Spectrometry Laboratory Analysis Report \#4103. Analytical Characterization and Pyrolysis Study of HFE-7000. Rutgers University; October 2004.

2. Hartman, T.G.: Phase 1 of PFH/FC-72 Pyrolysis Study: GC-MS and GC-FID Impurity Profiling of FC72 and Aldrich Lot \#18025DB n-Perfluorohexane (PFH) Samples. Laboratory Report \#4045-1. June 4, 2004.

3. Tortelli, V.; Tonelli, C.; and Cervaja, C.: Thermal Decomposition of Branched-Chain Perfluoroalkanes. J. Fluorine Chemistry 60: 1993; pp. 165-174.

4. Tortelli V. and Tonelli, C. (1994). Pyrolysis of Branched-Chain Perfluoroalkanes in the Presence of Halogens. J. Fluorine Chemistry 67: 1994; pp. 125128.

5. Perry, J.L.: The Interaction of Spacecraft Cabin Atmospheric Quality and Water Processing System Performance. SAE 2002-01-2300. Society of Automotive Engineers: Warrendale, PA; July 2002.

6. Yaws, C.L.; Hopper, J.R.; Wang, X.; and Rathinsamy, A.K.: Calculating Solubility and Henry's Law Constants For Gases in Water. Chemical Engineering. June 1999, pp. 102-105.

7. Zeppa, S.J.: Molecular Sieve Contaminant Characterization Test Report. LMSC/F280519. Lockheed: Sunnyvale, CA; September 1991.

8. Lam, C-W. Memorandum JSCTox-Lam-021119, November 19, 2002, p. 4.

9. Fire due to ignition of the solid oxygen source [ K] cartridge during SFOG operation. International Space Station ONS/Hazard Report RSCE-0058-05. Attachments 1 and 8. RSC Energia: Korolev, Russia; 2004.

10. Evaluation of Decomposition Properties of Perfluorinated Electronic Liquid Using Coupled Thermogra-
vimetric-Infrared Techniques. ED36A(04-061). NASA Marshall Space Flight Center; 2004.

11. Hartman, T.G.: Phase I of PFH/FC-72 Pyrolysis Study-GC-MS \& GC-FID Impurity Profiling of F2 Chẹmicals Ltd n-Perfluorohexane (PFH) Sample. Lab Report \#4045-2. Rutgers University; New Jersey; June 17, 2004.

12. Hartman, T.G.: Mass Spectrometry Laboratory Analysis Report \#4045-3. Phase II of PFH/FC-72 Pyrolysis Study-Pyrolysis of n-Perfluorohexane (PFH) Samples from Aldrich Chemical and F2 Chemicals Ltd with GC-MS/GC-FID Chemical Analysis of Pyrolysis Products. Rutgers University; New Jersey; July 22, 2004.

13. Trowbridge, L.D.: Potential Hazards Relating to Pyrolysis of $\mathrm{C}^{-\mathrm{C}_{4}} \mathrm{~F}_{8}$ in Selected Gaseous Diffusion Plant Operations. ORNL/TM-13758. Oak Ridge National Laboratory. March 1999.

14. Trowbridge, L.D.: Potential Hazards Relating to Pyrolysis of $\mathrm{c}-\mathrm{C}_{4} \mathrm{~F}_{8} \mathrm{O}, \mathrm{n}-\mathrm{C}_{4} \mathrm{~F}_{10}$ and $\mathrm{c}-\mathrm{C}_{4} \mathrm{~F}_{8}$ in Selected Gaseous Diffusion Plant Operations. ORNL/TM2000/68. Oak Ridge National Laboratory. March 2000.

15. van Gurp, R.A. and Bryan, P.C.: Semi-Empirical AM1 Study on the Hydrolysis Reactions of Perfluoroisobutene in the Gas Phase. Journal of Fluorine Chemistry 70 (1995) 193-196.

16. Eapen, K.C.; Chen, L.S.; and Chen, G.J.: Thermal Decomposition of Low-Molecular Weight Perfluoroalkylethers. Journal of Fluorine Chemistry. 81 (1997) 143-151.

17. Levine, I.N.: Physical Chemistry. Second Edition. McGraw-Hill; 1983. pp. 522-526.

18. Ibid., pp. 528-530.

19. Levenspiel, O. Chemical Reaction Engineering. Second Edition. John Wiley and Sons; 1972, pp. 107-117.

20. Robinson, R.N.: Chemical Engineering Reference Manual. Fourth Edition. Professional Publications. 1988, pp. 11-16 to 11-19.

21. Perry, J.L.: Environmental Control and Life Support System Compatibility and Remedial Responses for Perfluorohexane-based Fluids. NASA Memorandum FD21(04-121). NASA MSFC; September 17, 2004.

22. Spacecraft Maximum Allowable Concentrations for Selected Airborne Contaminants. Volume 4. National Academy Press; Washington, D.C.; 2000, pp. 17-41.

23. Spacecraft Maximum Allowable Concentrations for Selected Airborne Contaminants. Volume 1. National Academy Press; Washington, D.C.; 1994, pp. 39-59.

\section{CONTACT}

Jay L. Perry

National Aeronautics and Space Administration

George C. Marshall Space Flight Center

Mail Stop El12

Marshall Space Flight Center, Alabama 35812 USA 
jay.L.Perry@nasa.gov

William A. Arnold, Ph.D.

ZIN Technologies, Inc.

NASA Glenn Research Center

2001 Aerospace Parkway

Brook Park, Ohio 44142 USA

William.Arnold@zin-tech.com 